\title{
The Role of L-ornithine-L-aspartate in the Management of Minimal Hepatic Encephalopathy among Patients with Liver Cirrhosis: a Systemic Review and Meta-analysis
}

\author{
Henry Winston C. Li, ${ }^{1}$ Maria Ana Louise M. Naidas, ${ }^{1}$ Karen Anjela M. Mondragon ${ }^{1}$ and Ruter M. Maralit ${ }^{2}$ \\ ${ }^{1}$ Department of Medicine, Philippine General Hospital, University of the Philippines Manila \\ ${ }^{2}$ Section of Gastroenterology, Department of Medicine, College of Medicine and Philippine General Hospital, University of the Philippines Manila
}

\begin{abstract}
Objective. To evaluate the efficacy of L-ornithine-L-aspartate (LOLA) in improving minimal hepatic encephalopathy in adult patients with liver cirrhosis.

Methods. A search in PubMed, Cochrane Library, Google Scholar, and Medline was made obtaining four qualified randomized controlled trials. Studies included adult cirrhotic patients with minimal hepatic encephalopathy measured by the number connection test (NCT-A, B), figure connection test (FCT-A, B), picture completion, block design test, and critical flicker frequency (CFF) testing with a cut-off score of $<39 \mathrm{~Hz}$. Methodologic assessment of studies was performed using Cochrane Collaboration Risk of Bias Tool and Review Manager (RevMan) version 5.3 for statistical analysis.
\end{abstract}

Results. Of the 29 studies identified, 4 fulfilled the inclusion criteria, which entailed analysis of 238 participants (LOLA: 116, Control: 122). Three out of the four studies were used in meta-analysis and one study was analyzed separately due to a difference in the neuropsychometric measure. The metaanalysis favored experimental group (LOLA), with a mean difference of 2.29 (95\% Cl $0.72-3.86)$, $\mathrm{p}$-value $=0.004$, and an $\mathrm{I} 2$ of $18 \%$.

Conclusion. LOLA provided great potential in managing encephalopathy since treating earlier related to better survival and prevention of disease progression. The results of our study supported such evidence and its use may be encouraged.

Key Words: cirrhosis, hepatic encephalopathy, LOLA

\section{INTRODUCTION}

Liver cirrhosis remains to be prevalent in the Philippines. According to the health statistics data published by the WHO last May 2014, liver disease occurs in 10,388 or $1.99 \%$ of deaths in our country. ${ }^{1}$ The etiology

Poster presented at the Myanmar Internal Medicine Conference, September 29 - October 1, 2017, Melia Hotel, Yangon, Myanmar. Finalist - UP PGH Internal Medicine Department Research Forum, November 25, 2016.

Corresponding author: Henry Winston C. Li, MD

Department of Medicine

Philippine General Hospital

University of the Philippines Manila

Taft Avenue, Ermita, Manila 1000 Philippines

Telephone: +63922 8946754

Email:winolps24@yahoo.com of cirrhosis spans from infectious including chronic hepatitis and schistosomiasis to alcoholism, malignancy, and toxininduced process. In a study done last 2013, an estimated 7.3 million Filipinos (16.7\% of the adult population) were found to be chronically infected with hepatitis B virus, which may also lead to hepatocellular carcinoma. ${ }^{2}$

Patients with cirrhosis usually have frequent hospitalizations from complications of end stage disease such as bleeding varices, recurrent ascites, and encephalopathy. The emergence of new therapies has provided for a better quality 
of life for these patients, especially in our country where opportunities for liver transplantation and TIPS (transjugular intrahepatic portosystemic shunt) are scarce. ${ }^{2}$ Review of recent literature included addition of branched chain amino acids to standard regimens. In fact, current international practice guidelines such as the American Association for the Study of Liver Diseases 2014 Guidelines for Chronic Liver Disease have recommended the use of both oral and intravenous branched-chain amino acids as an alternative or additional agent for patients with end-stage liver disease with accompanying hepatic encephalopathy who are nonresponsive to conventional therapy. ${ }^{3}$

In liver cirrhosis, impairment in ureagenesis increases the levels of toxic ammonia in the circulation resulting in encephalopathy. The use of $\mathrm{L}$-ornithine-L-aspartate (LOLA) for this purpose stems from its ability to promote ureagenesis and glutamine synthetase activity in the liver. The component amino acids ornithine and aspartate are crucial factors in the biochemical pathways that detoxify ammonia. LOLA may be effective in treating hepatic encephalopathy because the drug alters the gastrointestinal tract flora, directly decreases cerebral edema, enhances the conversion of ammonia to urea and glutamine, antagonizes benzodiazepine-like substances, and directly increases dopamine concentrations in the brain. ${ }^{4}$ Though widely available, the use of LOLA has not been prevalent possibly due to lack of local data and experience.

Last 2013, a meta-analysis by Bai et al incorporated eight randomized controlled trials which revealed promising results - LOLA was found to decrease ammonia levels in patients with both overt and minimal hepatic encephalopathy. ${ }^{5}$ Since its inception, numerous trials have emerged, enriching the pool of data for this promising treatment. However, unlike previous studies where surrogate measures of ammonia were used as a basis for improvement, this study focused on improvement of encephalopathy, specifically the minimal form, as evidenced by the critical flicker frequency test.

The critical flicker frequency test is a common tool and remains to be a simple, reliable, and accurate test without any age or literacy dependence for the diagnosis of hepatic encephalopathy. A recent study found it to have a sensitivity of $61 \%$ (95\% CI: 55-67), and a specificity of 79\% (95\% CI: 75-83). ${ }^{6,7}$ The CFFT has the advantage of not depending on variables such as language, verbal fluency, numeracy or numerics, and therefore studies into its use have been performed widely including countries in Asia. Interestingly, the device was initially used as an ophthalmological test used to measure visual acuity and to screen for optic nerve lesions. This test measures the frequency at which the patient perceives that a fused/single light becomes a flickering light. The device induces a stepwise decrease in frequency from 60 to $25 \mathrm{~Hz}$ and is being done multiple times (usually 8-10) to allow calculation of the mean and standard deviation. In the light of evaluating hepatic encephalopathy, the score is interpreted as positive when the score is $<39 \mathrm{~Hz}$ as supported by several validation cohorts and meta-analysis. An increase in such score denotes improvement in hepatic encephalopathy.

Likewise, we excluded studies involving moderate and severe hepatic encephalopathy to remove confounding factors, which may contribute to the decline in sensorium. A more severe disease tends to correlate more with other sources of encephalopathy such as electrolyte derangements and sepsis. In summary, we aimed to gather new findings to shed light on the efficacy of LOLA in improving outcomes in minimal hepatic encephalopathy in patients with end-stage liver disease.

\section{General objective}

The purpose of this study was to evaluate the efficacy of L-ornithine-L-aspartate in improving minimal hepatic encephalopathy.

\section{Specific objectives}

To evaluate the efficacy of oral L-ornithine-L-aspartate on mild hepatic encephalopathy in patients with cirrhosis with the use of neuropsychometric tests.

To evaluate the safety of the use of L-ornithine-Laspartate in the treatment of mild encephalopathy among adult cirrhotic patients as evidenced by the number of adverse events.

\section{METHODS}

\section{Databases and search strategy}

The electronic databases PubMed, Cochrane Library, Google Scholar, and Medline were used to to retrieve articles from January 1990 to June 2016. The search terms used were: L-ornithine-L-aspartate (LOLA), efficacy, hepatic encephalopathy, and liver cirrhosis. No language and publication restrictions were used during the search of articles. We also obtained primary sources from tracking references from hand searches in review papers and original articles. Only original data were used in the meta-analysis.

\section{Eligibility criteria}

The articles selected in the study included randomized controlled trials conducted among adult cirrhotic patients at least 18 years of age with minimal hepatic encephalopathy objectively measured by various neuropsychometric testing including the number connection test (NCT-A, B), figure connection test (FCT-A, B), picture completion, and block design test. Some studies also utilized the critical flicker frequency testing with a cut-off score of $<39$ as described. All patients were treated with the use of oral L-ornithine$\mathrm{L}$-aspartate per orem or via infusion versus placebo. Some studies also compared placebo against the use of rifaximin and lactulose. The primary outcome that was primarily evaluated was the improvement of patient's mental state via critical flicker frequency test. 
Studies which were not RCTs including retrospective studies and case reports and reviews were excluded. Furthermore, articles including clinical subjects with overt encephalopathy or with concomitant serious condition such as an active infection i.e. spontaneous bacterial peritonitis, sepsis, acute complications of cirrhosis including gastrointestinal hemorrhage and hepatorenal syndrome were also excluded from the study.

\section{Selection of studies}

The meta-analysis included trials that focused on the treatment effect of giving L-ornithine L-aspartate in managing minimal hepatic encephalopathy. Two independent reviewers extensively assessed and identified available trials by applying the inclusion and exclusion criteria mentioned above with disagreements resolved through discussion and consultation with a third reviewer.

This review was able to identify 23 references from various electronic databases mentioned above. Three additional articles were retrieved by manually searching the identified papers' reference list. Out of the 29 studies gathered, only 10 articles were fully retrieved and assessed for eligibility. Considering the inclusion and exclusion criteria mentioned, only three controlled trials were statistically analyzed (Figure 1).

\section{Quality assessment of selected studies}

Assessment of the quality of included trials was performed using the Cochrane Collaboration Risk of Bias Tool. Domains including method of randomization, allocation concealment, blinding, follow-up rate, and intention to treat analysis were taken into account. (See Appendices A-D)

They were evaluated as to the risk of bias with their corresponding basis for judgment. The qualities of the 4 randomized studies are summarized in Figures 2 and 3.

Overall, there is essentially low risk of bias for most of the domains.

However, blinding of study participants and personnel were not done in 2 studies, which poses a great threat to the overall validity.

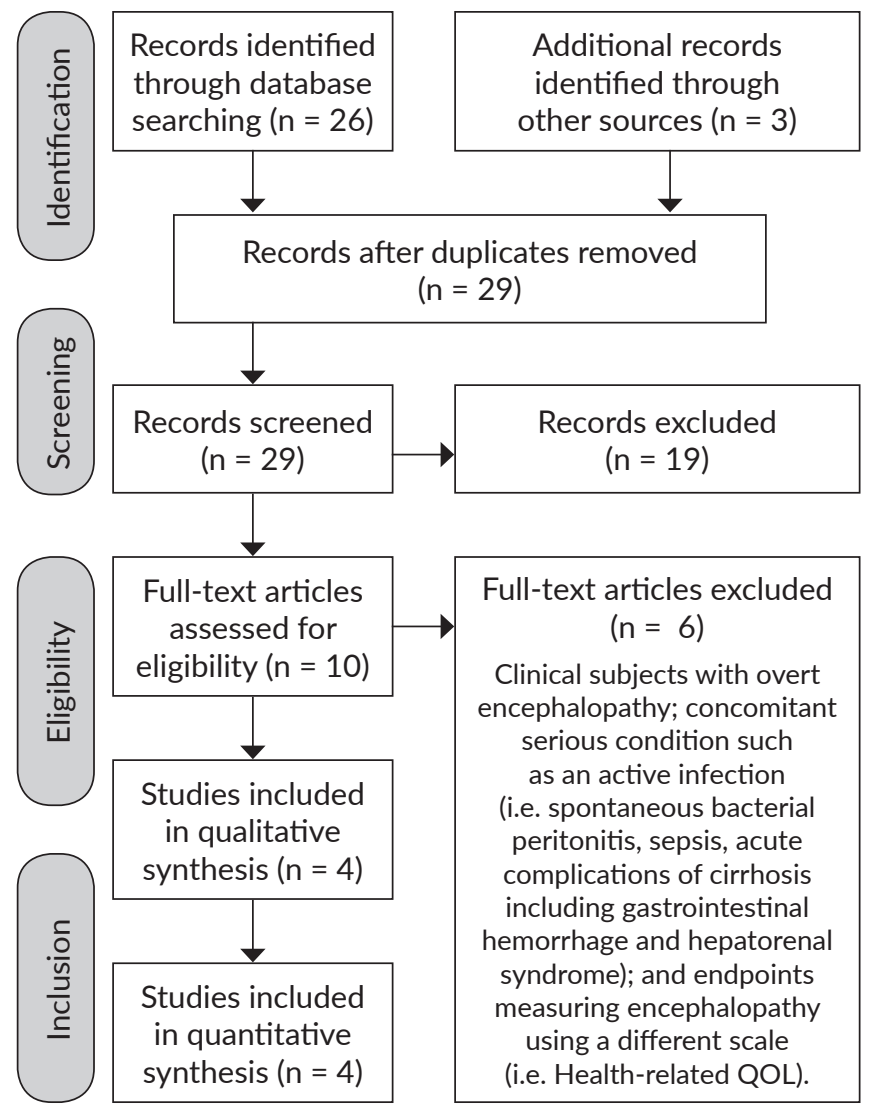

Figure 1. Prisma flow chart.

\section{Statistical synthesis}

All statistical analyses done in the study were performed using RevMan 5.3 provided by The Cochrane Collaboration. Heterogeneity was assessed using the chi- square statistic and a p-value of less than 0.05 was considered to represent significance. The statistical strength was identified by overall effect size $Z$ and heterogeneity index $\mathrm{I}^{2}$. Additionally, sensitivity analyses that were conducted to determine the stability of the overall effects were performed by the random effects model.

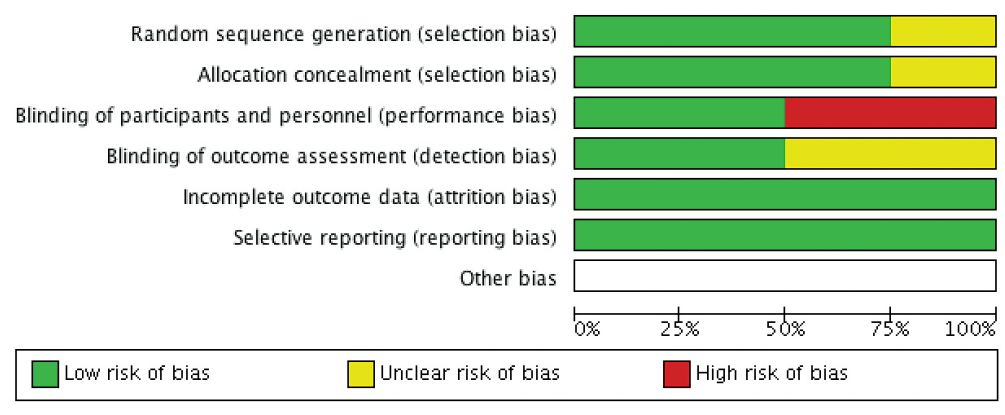

Figure 2. Risk of bias.

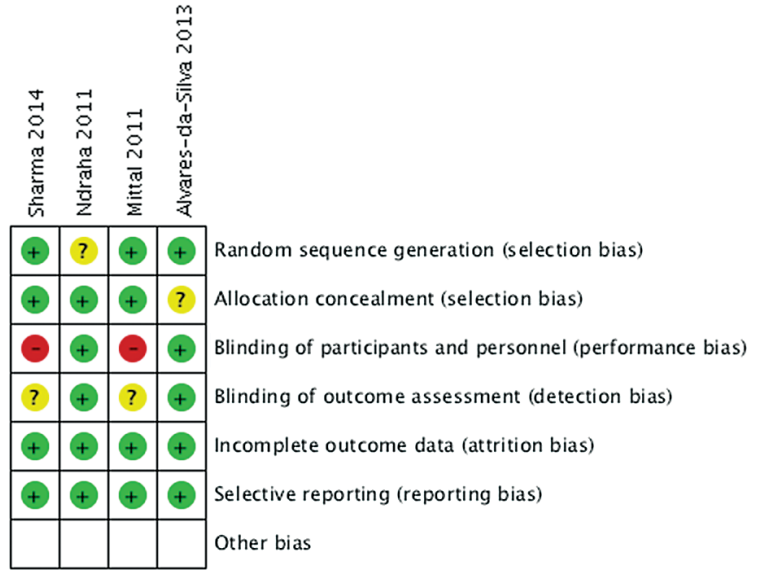

Figure 3. Summary of risk of bias. 


\section{RESULTS}

\section{Characteristics of included studies}

The characteristics of the included studies that assessed the efficacy of LOLA in reversing minimal hepatic encephalopathy are shown in Table 1. Four studies presented results on reversing minimal hepatic encephalopathy as the outcome. Three studies that were pooled included improvement of encephalopathy as evidenced by the critical flicker frequency test, which included a total of 158 participants (intervention: 76; control: 82). Both RCT1 and $\mathrm{RCT} 3$ relied on the $\mathrm{CFF}<39 \mathrm{~Hz}$ and at least 2 abnormal tests out of the battery of neuropsychometric testing (NCT-A,B; Figure connection test, etc.) in including patients deemed to have minimal hepatic encephalopathy while RCT2 solely depended on the CFF (39 Hz) and RCT 4 on 2 abnormal NPTs as a marker of mental status. The doses of LOLA used ranged from $5 \mathrm{~g}-6 \mathrm{~g}$ TID. The average duration of treatment ranged from 2-12 weeks. The baseline clinical characteristics of the participants in each trial were demonstrated as well with mean age of 48.1 years old. The total number of pooled subjects from the clinical trial summed up to 160 patients with 78 (49\%) and $82(51 \%)$ for the treatment and control groups, respectively. Of note is the prevalence of male participants enrolled in the included randomized trials comprising of $53.6-94.1 \%$ in each subgroup. The CFF score was reevaluated after giving of both treatment (LOLA) and placebo in their respective groups. Paired T-test was essentially used to measure significance in the difference of CFF score on both pretreatment and posttreatment accordingly.

\section{Primary Outcome}

The means listed in the studies included above represents the differences between the CFF score before and after treatment on both respective groups (LOLA vs placebo).

An attempt to reach the authors of each RCT was made to procure the raw data and derive the standard deviation based on such information. However, this was to no avail. Hence, the standard deviations presented in both groups of each study were derived by calculating with the following formula; $\left(\mathrm{SD}^{2}+\mathrm{SD} 2^{2}\right)$ where $\mathrm{S} \mathrm{D} 1^{2}$ was for the $\mathrm{SD} 2^{2}$ presented on pretreatment and SD2 on post treatment. [SOMETHING MISSING]

Grouped analysis of the three studies of similar outcomes collectively favored the experimental (LOLA) group with a mean difference of 2.29 (95\% CI $0.72-3.86$ ). The pooled analysis had a significant $\mathrm{p}=0.004$ and an $\mathrm{I}^{2}$ of $18 \%$ proved the data to have no significant heterogeneity (Figure 4).

The fourth study (Mitta et al., 2011) evaluated minimal hepatic encephalopathy by means of a different neuropsychometric test - the number connection test (NCT) and figure connection test (FCT). The measure for the primary outcome in this study was different compared to the 3 studies, hence was not included in the metaanalysis and was subsequently analyzed separately. In Mittal et al., the trial compared lactulose, probiotics, and L-ornithine L-aspartate (LOLA) in treatment of minimal hepatic encephalopathy and effect on HRQoL by Sickness Impact Profile questionnaire. They also measured the changes in NCT and FCT scores after the 3 interventions were given over the course of 12 weeks as an indicator for improvement

Table 1. Baseline characteristics of included studies

\begin{tabular}{lllll} 
& $\begin{array}{l}\text { RCT1 LOLA/Control } \\
\text { Sharma }^{8}\end{array}$ & $\begin{array}{l}\text { RCT2 LOLA/Control } \\
\text { Ndraha }^{9}\end{array}$ & $\begin{array}{l}\text { RCT3 LOLA/Control } \\
\text { Alvares da Silva }^{10}\end{array}$ & $\begin{array}{l}\text { RCT4 LOLA/Control } \\
\text { Mittal }^{11}\end{array}$ \\
Age & $42 / 38$ & $53.2 / 51.8$ & $51.3 / 52.5$ & $42.15 / 41.20$ \\
Male (\%) & $64.5 / 67$ & $94.1 / 88.2$ & $53.6 / 48.6$ & $77.5 / 75$ \\
Female (\%) & $35.5 / 33$ & $5.9 / 11.8$ & $46.4 / 51.4$ & $22.5 / 25$ \\
Percentage of viral-induced cirrhosis (\%) & $41.9 / 35.5$ & $\mathrm{NS}$ & $\mathrm{NS}$ & $35 / 35$ \\
Percentage of alcohol-induced cirrhosis (\%) & $38.7 / 32.3$ & $\mathrm{NS}$ & $\mathrm{NS}$ & $42.5 / 35$ \\
Child Pugh B (\%) & $42.9 / 26.67$ & $88.2 / 94.1$ & $89.3 / 80$ & $\mathrm{NS}$ \\
Child Pugh C (\%) & $35.48 / 40$ & $11.8 / 5.9$ & $\mathrm{NS}$ & $\mathrm{NS}$ \\
Treatment Duration & 8 weeks & 2 weeks & 8 weeks & 12 weeks \\
Dosage of LOLA used & 6g LOLA PO TID & $6 g$ LOLA PO TID & $5 \mathrm{~g}$ LOLA PO TID & $6 \mathrm{~g}$ LOLA TID \\
Country & Saudi Arabia & Indonesia & Brazil & India \\
Number of Participants & $31 / 30$ & $17 / 17$ & $28 / 35$ & $40 / 40$ \\
\hline
\end{tabular}

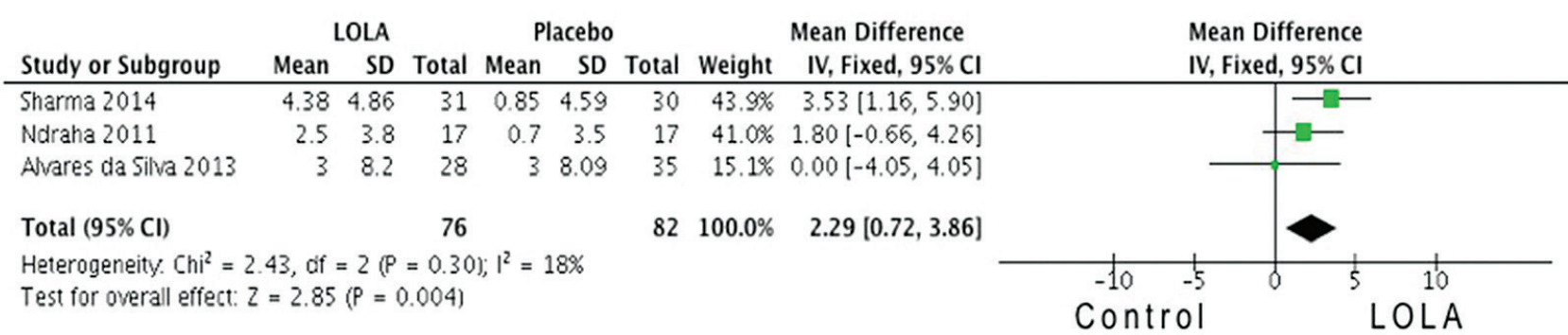

Figure 4. Forest plot of incidence of CIN between treatment (Cordyceps) and control (standard therapy) group. 
of minimal hepatic encephalopathy. Results revealed that LOLA improved psychometric scores $(1.55 \pm 1.28)$ versus no treatment $(0.39 \pm 0.8)(p$-value $<0.000)$ by intention to treat analysis.

\section{Secondary outcome}

Of the 4 studies included in the analysis, none included safety as an outcome of interest.

\section{DISCUSSION}

Alternative therapies for patients with end stage liver disease have emerged in recent years. ${ }^{3}$ In this study, we looked into the efficacy of L-ornithine $\mathrm{L}$-aspartate in reversing minimal hepatic encephalopathy in patients with liver cirrhosis. The results of our pooled analysis proved that giving LOLA decreased and reversed minimal hepatic encephalopathy as measured by neuropsychometric testing.

Hepatic encephalopathy, in its lowest form, also widely known as minimal hepatic encephalopathy; is described as aberrancies in psychometric measurement with regard to attention, working memory, psychomotor and visuospatial ability, as well as electrophysiological and other functional brain measures. ${ }^{12}$ The importance of both screening for and treating early stages of encephalopathy stems from the fact that it has been shown to be a marker of development of overt hepatic encephalopathy and correlates more with an overall poorer prognosis and decreased quality of life in cirrhotic individuals. ${ }^{3,12}$

In the Philippines, current practice involves treating overt rather than covert encephalopathy. Standard therapy includes the use of first line agents, which include: lactulose, rifaximin, metronidazole, or neomycin. The most widely used agent, lactulose acts to provide both bacteriostatic and cathartic effects with the enhancement of conversion of ammonia to ammonium which are then being excreted into the feces and eliminated.

Though not commonly utilized, avenues regarding the addition of novel agents such as LOLA have already been entertained. To date, LOLA has been used but only in treatment-resistant cases and only as an add-on and alternative. LOLA stimulates the urea cycle and glutamine synthesis, which is an important mechanism in the detoxification of ammonia. This agent improves the ability of the liver and other organs to detoxify ammonia systematically in contrast to lactulose, which acts locally in the intestine.

Discrepancies in the direct correlation between ammonia concentration and the severity of hepatic encephalopathy in patients with cirrhosis, have contributed to the general consensus that while ammonia has an irrefutable role in the pathogenesis of hepatic encephalopathy, it may not be solely responsible for the neurocognitive sequelae and other factors might contribute to this process. ${ }^{13}$ Nevertheless, Alvares da Silva et al evaluated the change in ammonia between LOLA and the control group. This was analyzed and was proven to be not significant with a $\mathrm{p}$-value of 0.58 and 0.68 , respectively. ${ }^{10}$

Safety is one of the variables we aimed to look into; however, none of the studies retrieved included it in their analysis. Perhaps the previous experience of health practitioners along with robust studies proving this intervention to have rare adverse events, intolerance, and death made the pursuit of this outcome less significant. In general, studies have reported side effects which were minor nausea, vomiting, and sensation of palpitations. ${ }^{14,15}$

\section{Implications in clinical practice}

The use of LOLA provides a great potential in managing encephalopathy since treating in an early stage converts into a better survival rate and prevention of disease progression as mentioned in several cohort studies. The results of our study highly support such evidence and hence its use may be encouraged in the local setting. However, one of the limitations of the results is its dependence on the objective tests (NPTs and CFF) as a measure of mental state, which is understandable in order to establish uniformity in assessment and baseline characteristics. While such tests are both not routinely used and available in our setting, our reliance on the basis of the patient's clinical status should still principally guide us in evaluating its use. Accordingly, perhaps the role of LOLA as a means of prophylaxis for hepatic encephalopathy can be utilized. Since minimal hepatic encephalopathy has covert manifestations and the use of neuropsychometric testing in our country is not widely practiced, the use of LOLA in chronic liver disease with no identifiable symptoms of encephalopathy may be of benefit as well. In addition, one of its desired advantages is its minimal side effects (e.g. nausea) and tolerability, which is also important, as patients with end stage liver disease inherently possess compounding morbidities.

\section{Implications in research}

The emergence of the use of LOLA in clinical trials signifies its wide relevance in clinical practice. Ultimately, we highly recommend to increase the number of clinical subjects and consider both subjective and objective measures in evaluating improvement in mental state so that its use may be well-translated in clinical practice. Allowing more observation time and longer duration of treatment are also encouraged to further assess the effectiveness of LOLA in cirrhotic patients with encephalopathy.

In summary, this meta-analysis of 4 studies indicates that the use of LOLA may improve minimal hepatic encephalopathy in patients with liver cirrhosis.

We emphasize that encephalopathy exists in covert forms and therefore recommend further research into other treatment options as it has been shown to affect prognosis and quality of life. Further studies may explore on the role of LOLA on acute and overt encephalopathy as well as differences in outcome depending on the duration of treatment. 


\section{Statement of Authorship}

All authors have approved the final version submitted.

\section{Author Disclosure}

All the authors declared no conflict of interest.

\section{Funding Source}

This paper was partially funded by the Philippine General Hospital and the authors.

\section{REFERENCES}

1. Global Health Observatory (GHO) data. World Health Organization [Online]. [cited 2016 Oct]. Available from http://www.who.int/gho/ alcohol/harms_consequences/deaths_liver_cirrhosis/en/.

2. Gish RG, Sollano JD Jr, Lapasaran A, Ong JP. Chronic hepatitis B virus in the Philippines. J Gastroenterol Hepatol. 2016; 31(5):945-52. doi:10.1111/jgh.13258.

3. Vilstrup H, Amodio P, Bajaj J, et al. Hepatic encephalopathy in chronic liver disease: 2014 Practice Guideline by the American Association for the Study of Liver Diseases and the European Association for the Study of the Liver. Hepatology. 2014; 60(2):715-35. doi:10.1002/ hep. 27210.

4. Sikorska H, Cianciara J, Wiercinska-Drapalo A. Physiological functions of L-ornithine and L- aspartate in the body and the efficacy of administration of L-ornithine-L-aspartate in conditions of relative deficiency. Pol Merkur Lekarski. 2010; 28(168):490-5.

5. Bai M, Yang Z, Qi X, Fan D, Han G. L-ornithine-L-aspartate for hepatic encephalopathy in patients with cirrhosis: a meta-analysis of randomized controlled trials. J Gastroenterol Hepatol. 2013; 28(5):783-92. doi:10.1111/jgh.12142.

6. Torlot FJ, Mcphail MJW, Taylor-Robinson SD. Metaanalysis: the diagnostic accuracy of critical flicker frequency in minimal hepatic encephalopathy. Aliment Pharmacol Ther. 2013; 37(5):527-36. doi:10.1111/apt.12199.
7. Sharma P, Sharma BC, Puri V, Sarin SK. Critical flicker frequency: diagnostic tool for minimal hepatic encephalopathy. J Hepatol. 2007; 47(1):67-73. doi:10.1016/j.jhep.2007.02.022.

8. Sharma K, Pant S, Misra S, et al. Effect of rifaximin, probiotics, and 1-ornithine 1- aspartate on minimal hepatic encephalopathy: a randomized controlled trial. Saudi J Gastroenterol. 2014; 20(4):22532. doi:10.4103/1319-3767.136975.

9. Ndraha S, Hasan I, Simadibrata M. The effect of L-ornithine-Laspartate and branched- chain amino acids on encephalopathy and nutritional status in liver cirrhosis with malnutrition. Acta Med Indones. 2011; 43(1):18-22.

10. Alvares-Da-Silva MR, de Araujo A, Vicenzi JR, et al. Oral 1-ornithine1-aspartate in minimal hepatic encephalopathy: a randomized, doubleblind, placebo-controlled trial. Hepatol Res. 2014; 44(9):956-63. doi:10.1111/hepr.12235.

11. Mittal VV, Sharma BC, Sharma P, Sarin SK. A randomized controlled trial comparing lactulose, probiotics, and L-ornithine L-aspartate in treatment of minimal hepatic encephalopathy. Eur J Gastroenterol Hepatol. 2011; 23(8):725-32. doi:10.1097/meg.0b013e32834696f5.

12. Ortiz M, Jacas C, Córdoba J. Minimal hepatic encephalopathy: diagnosis, clinical significance and recommendations. J Hepatol. 2005; 42 Suppl(1):S45-53. doi:10.1016/j.jhep.2004.11.028.

13. Aldridge DR, Tranah EJ, Shawcross DL. Pathogenesis of hepatic encephalopathy: role of ammonia and systemic inflammation.J Clin Exp Hepatol. 2015, 5 (Suppl 1):S7-S20. doi:10.1016/j.jceh.2014.06.004.

14. Poo JL, Gongora J, Sanchez-Avila JF, et al. [81] Efficacy and safety of L-ornithine-L-aspartate (LOLA) administration. Open label randomized controlled trial versus lactulose in cirrhotic patients with hyperammonemic hepatic encephalopathy. J Hepatol. 2007; 46 (suppl 1):S36. doi:10.1016/s0168-8278(07)61679-1.

15. Rees CJ, Oppong K, Al Mardini H, Hudson M, Record CO. Effect of L-ornithine-L-aspartate on patients with and without TIPS undergoing glutamine challenge: a double blind, placebo controlled trial. Gut. 2000; 47(4):571-4. doi:10.1136/gut.47.4.571.

\section{Acta Medica Philippina The National Health Science Journal}

Now available for free at the Apple app store and Google play store.

Available on the App Store

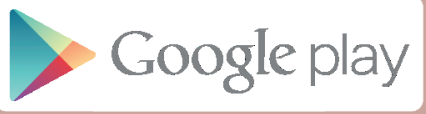




\section{APPENDICES}

Appendix A. Data extraction form for Trial 1

\begin{tabular}{|l|l|l}
\hline Trial ID 1 & Extractor: Li/Naidas & Year of Publication: 2013 \\
\hline
\end{tabular}

Title: Oral L-ornitine-L-aspartate (LOLA) in cirrhotic patients with minimal hepatic encephalopathy (MHE): final results of a randomized doubleblind placebo-controlled trial

Authors: Alvares-da-Silva MR, Araujo AD, Vicenzi JR, Oliveira FB, Silva GV, Schacher FC, Oliboni LS , Magnus AM, Kruel LR and Fernandes LN Citation: Alvares-Da-Silva MR, Araujo AD, Vicenzi JR, et al. Oral I- ornithine-I-aspartate in minimal hepatic encephalopathy: a randomized, double-blind, placebo-controlled trial. Hepatology Research. 2013;44(9):956-963. doi:10.1111/hepr.12235.

\section{Participants}

Inclusion criteria:

1. MHE defined by psychometric tests: NCT A/B, digit symbol substitution test; cirrhosis based on liver biopsy or combination of PE, labs and imaging

Exclusion criteria:

1. Diuretic therapy;

2. MHE precipitated by infection, GI bleeding, constipation;

3. Overt $\mathrm{HE}$ at baseline or with more than one clinically evident episodes in the last 6 months;

4. Patients taking psychoactive drugs, alcohol, or HE-intended medicines other than lactulose

\section{Intervention}

Experimental group:

LOLA (oral, $5 \mathrm{~g}$ TID) for 60 days

Control/Comparison group:

Placebo (fructose, citrate, Na citrate, mannitol, povidone, Na cyclamate, saccharine)

\section{Method}

Randomized, double-blind placebo-controlled trial

Quality/Assessment/Risk of Bias Table

\begin{tabular}{|l|l|l|}
\hline \multicolumn{1}{|c|}{ Domain } & \multicolumn{1}{c|}{$\begin{array}{c}\text { Judgment } \\
\text { Low Risk/High Risk/Unclear }\end{array}$} & Done with computer-generated random tables. \\
\hline $\begin{array}{l}\text { Method of random sequence } \\
\text { generation (Selection bias) }\end{array}$ & Low risk & Not stated \\
\hline $\begin{array}{l}\text { Method of allocation concealment } \\
\text { (Selection bias) }\end{array}$ & Unclear & $\begin{array}{l}\text { Number of patients withdrawn from study were identified. Intent- } \\
\text { to-treat analysis. }\end{array}$ \\
\hline $\begin{array}{l}\text { Incomplete outcome data/Loss of } \\
\text { participant to follow up (Attrition bias) }\end{array}$ & Low risk & Double-blinded design \\
\hline $\begin{array}{l}\text { Blinding of participants and personnel } \\
\text { (Performance bias) }\end{array}$ & Low risk & Double-blinded design \\
\hline $\begin{array}{l}\text { Blinding of outcome assessment } \\
\text { (Detection bias) }\end{array}$ & Low risk & $\begin{array}{l}\text { Number of patients withdrawn from study were identified. Intent- } \\
\text { to-treat analysis }\end{array}$ \\
\hline $\begin{array}{l}\text { Selective Reporting/Intention to treat } \\
\text { analysis (Reporting bias) }\end{array}$ & Low risk & \\
\hline
\end{tabular}


Appendix B. Data extraction form for Trial 2

\begin{tabular}{|l|l|l}
\hline Trial ID 2 & Extractor: Li/Naidas & Year of Publication: 2011 \\
\hline
\end{tabular}

Title: The effect of L-ornithine L-aspartate and branch chain amino acids on encephalopathy and nutritional status in liver cirrhosis with malnutrition Authors: Suzanna Ndraha, Irsan Hasan, Marcellus Simadibrata

Citation: Ndraha S, Hasan I, Simadibrata M. The effect of L-ornithine-L-aspartate and branch chain amino acids on encephalopathy and nutritional status in liver cirrhosis with malnutrition. Acta Med Indonesia. 2011;43(1):18-22. http://www.inaactamedica.org/ archives/2011/21339541.pdf.

\section{Participants}

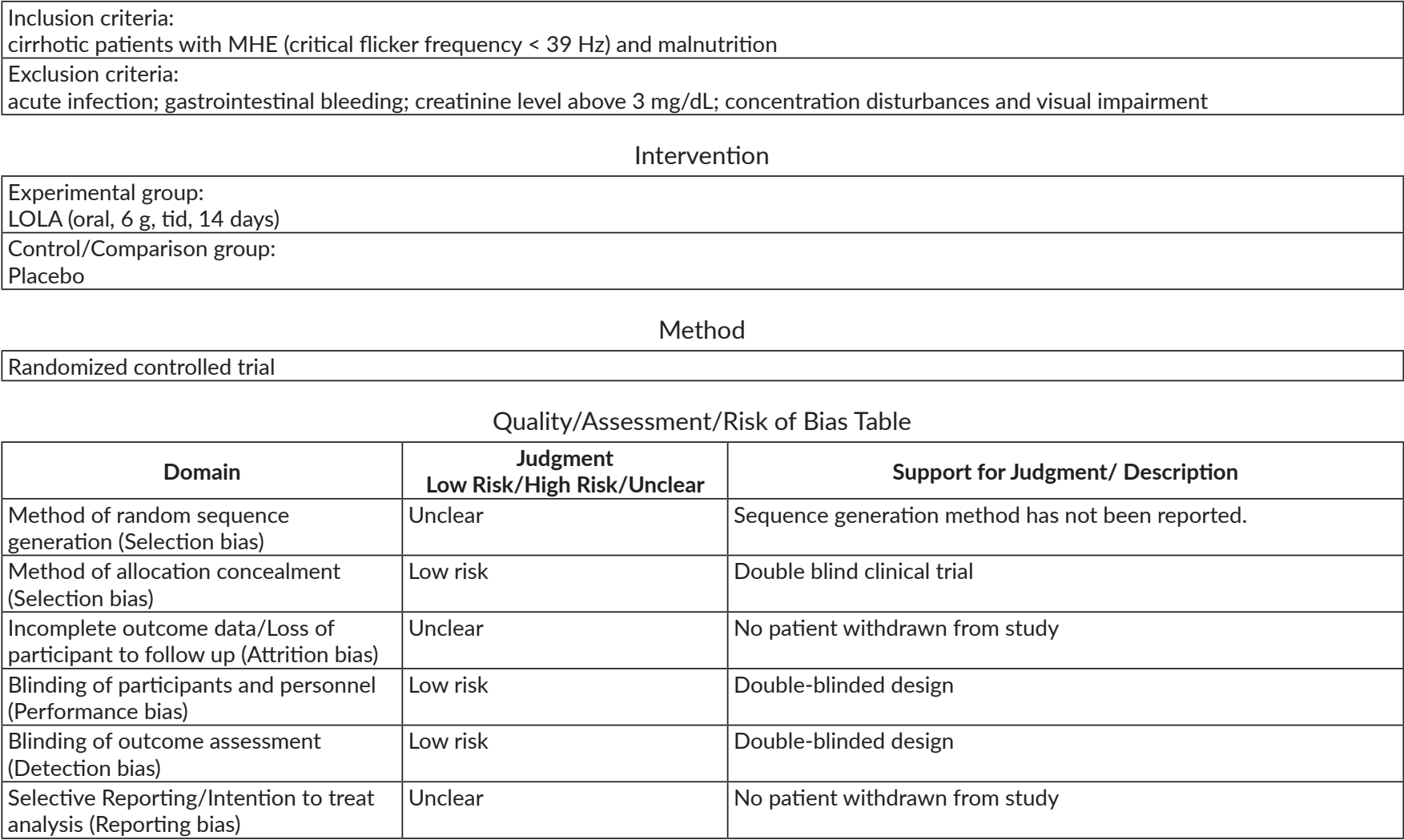


Appendix C. Data extraction form for Trial 3

\begin{tabular}{|l|l|l}
\hline Trial ID 3 & Extractor: Li/Naidas & Year of Publication: 2014 \\
\hline
\end{tabular}

Title: Effect of rifaximin, probiotics, and l-ornithine l-aspartate on minimal hepatic encephalopathy: a randomized controlled trial

Authors: Kapil Sharma, Sanjay Pant, Sriprakash Misra, Manisha Dwivedi, Alok Misra, Sushil Narang, Reshu Tewari, and Ajeet S. Bhadoria Citation: Sharma K, Pant S, Misra S, et al. Effect of rifaximin, probiotics, and I-ornithine l-aspartate on minimal hepatic encephalopathy: a randomized controlled trial. Saudi Journal of Gastroenterology. 2014;20(4):225. doi:10.4103/1319-3767.136975.

Inclusion criteria:

cirrhotic patients with MHE

Exclusion criteria:

Patients with overt HE or history of overt HE in the past 6 weeks, history of alcohol intake during the past 6 weeks, history of antibiotic or lactulose or probiotic use within the past 3 weeks, gastrointestinal bleed in the past 6 weeks, history of recent drug use ( $<6$ weeks), SBP or other infections in the past 7 days, renal insufficiency $(>1.5 \mathrm{mg} / \mathrm{L})$, electrolyte imbalance, Hepatocellular carcinoma

\section{Intervention}

Experimental group:

LOLA (oral $6 \mathrm{~g}$ TID)

Control/Comparison group:

Placebo

Method

Randomized controlled trial

Quality/Assessment/Risk of Bias Table

\begin{tabular}{|l|l|l|}
\hline \multicolumn{1}{|c|}{ Domain } & \multicolumn{1}{c|}{$\begin{array}{c}\text { Judgment } \\
\text { Low Risk/High Risk/Unclear }\end{array}$} & Sone with block randomization \\
\hline $\begin{array}{l}\text { Method of random sequence } \\
\text { generation (Selection bias) }\end{array}$ & Low risk & $\begin{array}{l}\text { The sequence remained concealed from the investigator and the } \\
\text { generator of random blocks. }\end{array}$ \\
\hline $\begin{array}{l}\text { Method of allocation concealment } \\
\text { (Selection bias) }\end{array}$ & Low risk & $\begin{array}{l}\text { Number and reason of probiotics, antibiotic/ lactulose use; } \\
\text { Gl bleed in past 6 weeks; SBP or other infection in the past 7 days }\end{array}$ \\
\hline $\begin{array}{l}\text { Incomplete outcome data/Loss of } \\
\text { participant to follow up (Attrition bias) }\end{array}$ & Low risk & The study was not blinded. \\
\hline $\begin{array}{l}\text { Blinding of participants and personnel } \\
\text { (Performance bias) }\end{array}$ & High risk & NR \\
\hline $\begin{array}{l}\text { Blinding of outcome assessment } \\
\text { (Detection bias) }\end{array}$ & Unclear risk & $\begin{array}{l}\text { Number of patients withdrawn from study were identified. } \\
\text { Intent-to-treat analysis }\end{array}$ \\
\hline $\begin{array}{l}\text { Selective Reporting/Intention to treat } \\
\text { analysis (Reporting bias) }\end{array}$ & Low risk & \\
\hline
\end{tabular}


Appendix D. Data extraction form for Trial 4

\begin{tabular}{|l|l|l}
\hline Trial ID 4 & Extractor: Li/Naidas & Year of Publication: 2010 \\
\hline
\end{tabular}

Title: A randomized controlled trial comparing lactulose, probiotics, and L-ornithine-L-aspartate in treatment of minimal hepatic encephalopathy

Authors: Vibhu Vibhas Mittala, Barjesh Chander Sharmaa, Praveen Sharma and Shiv Kumar Sarina

Citation: Mittal VV, Sharma BC, Sharma P, Sarina SK. A randomized controlled trial comparing lactulose, probiotics, and L-ornithine-L-aspartate in treatment of minimal hepatic encephalopathy. European Journal of Gastroenterology \& Hepatology. 2011;23(8):725-732.

Participants

Inclusion criteria:

cirrhotic patients with $\mathrm{MHE}$

Exclusion criteria:

1. overt $\mathrm{HE}$ based on detailed neurological examination or history of overt $\mathrm{HE}$ in the past 6 weeks,

2. recent history ( $<6$ weeks) of gastrointestinal bleeding,

3. active ongoing infection,

4. renal impairment with serum creatinine more than $1.5 \mathrm{mg} \%$,

5. electrolyte impairment (serum sodium $<130$ or $>150 \mathrm{meq} / \mathrm{dl}$, serum potassium $<3.0$ or $>5.5 \mathrm{meq} / \mathrm{dl}$ ),

6. recent alcohol use (< 6 weeks) as reported by the patient, recent use of antibiotic, lactulose, or LOLA (< 6 weeks), use of psychotropic drugs in last 6 weeks,

7. transjugular intrahepatic portosystemic shunt, shunt surgery,

8. hepatocellular carcinoma,

9. severe comorbidity as congestive heart failure, pulmonary disease, neurological and psychiatric problems impairing QoL, or poor vision precluding neuropsychiatric assessment

Intervention

Experimental group:

LOLA (oral, $6 \mathrm{~g}$, tid, 3 months)

Control/Comparison group:

probiotics (oral, 110 billion colony forming units, bid, 3 months) OR lactulose (oral, $30-60$ ml/d, 3 months, 2-3 stools/day) OR blank (Standard treatment for cirrhosis)

Method

Randomized controlled trial

Quality/Assessment/Risk of Bias Table

\begin{tabular}{|l|l|l|}
\hline \multicolumn{1}{|c|}{ Domain } & \multicolumn{1}{c|}{$\begin{array}{c}\text { Judgment } \\
\text { Low Risk/High Risk/Unclear }\end{array}$} & Done with computer generated random tables. \\
\hline $\begin{array}{l}\text { Method of random sequence } \\
\text { generation (Selection bias) }\end{array}$ & Low risk & The sequence were concealed until enrolment. \\
\hline $\begin{array}{l}\text { Method of allocation concealment } \\
\text { (Selection bias) }\end{array}$ & Low risk & $\begin{array}{l}\text { Number and reason of patients withdrawn from study were } \\
\text { identified. }\end{array}$ \\
\hline $\begin{array}{l}\text { Incomplete outcome data/Loss of } \\
\text { participant to follow up (Attrition bias) }\end{array}$ & Low risk & Open-labeled study without placebo \\
\hline $\begin{array}{l}\text { Blinding of participants and personnel } \\
\text { (Performance bias) }\end{array}$ & High risk & NR \\
\hline $\begin{array}{l}\text { Blinding of outcome assessment } \\
\text { (Detection bias) }\end{array}$ & Unclear risk & NR \\
\hline $\begin{array}{l}\text { Selective Reporting/Intention to treat } \\
\text { analysis (Reporting bias) }\end{array}$ & Unclear risk & \\
\hline
\end{tabular}

